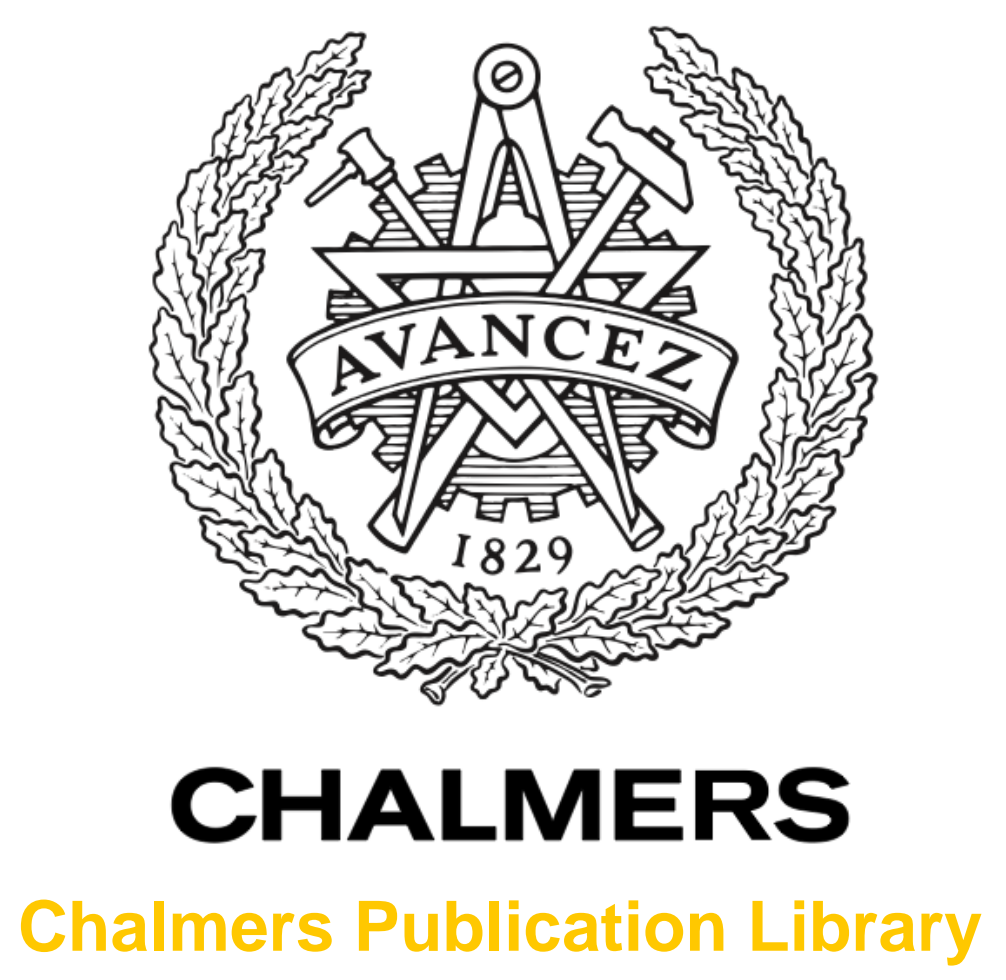

\title{
Crystal structure and proton conductivity of BaZr0.9Sc0
}

This document has been downloaded from Chalmers Publication Library (CPL). It is the author's version of a work that was accepted for publication in:

Journal of the American Ceramic Society (ISSN: 0002-7820)

Citation for the published paper:

Ahmed, I. ; Karlsson, M. ; Eriksson, S. et al. (2008) "Crystal structure and proton conductivity of BaZr0.9Sc0". Journal of the American Ceramic Society, vol. 91(9), pp. 3039-3044.

http://dx.doi.org/10.1111/j.1551-2916.2008.02547.x

Downloaded from: http://publications.lib.chalmers.se/publication/105960

Notice: Changes introduced as a result of publishing processes such as copy-editing and formatting may not be reflected in this document. For a definitive version of this work, please refer to the published source. Please note that access to the published version might require a subscription.

Chalmers Publication Library (CPL) offers the possibility of retrieving research publications produced at Chalmers University of Technology. It covers all types of publications: articles, dissertations, licentiate theses, masters theses, conference papers, reports etc. Since 2006 it is the official tool for Chalmers official publication statistics. To ensure that Chalmers research results are disseminated as widely as possible, an Open Access Policy has been adopted.

The CPL service is administrated and maintained by Chalmers Library. 


\title{
Crystal Structure and Proton Conductivity of $\mathrm{BaZr}_{0.9} \mathrm{Sc}_{0.1} \mathrm{O}_{3-\delta}$
}

\author{
Istaq Ahmed, ${ }^{\dagger \dagger}$ Maths Karlsson, ${ }^{\S}$ Sten-Gunnar Eriksson, ${ }^{\ddagger}$ Elisabet Ahlberg, ${ }^{\circledR}$ Christopher S. Knee ${ }^{\natural}$ \\ Kristian Larsson, ${ }^{\ddagger}$ Abul K. Azad, ${ }^{\|}$Aleksandar Matic, ${ }^{\S}$ and Lars Börjesson ${ }^{\S}$ \\ ${ }^{\ddagger}$ Department of Chemical and Biological Engineering, Chalmers University of Technology, \\ SE-412 96 Gothenburg, Sweden \\ ${ }^{\S}$ Department of Applied Physics, Chalmers University of Technology, SE-412 96 Gothenburg, Sweden \\ 'Department of Chemistry, University of Gothenburg, SE-412 96 Gothenburg, Sweden \\ "Department of Chemistry, University of St Andrews, Fife KY 16 9ST, Scotland, UK
}

\begin{abstract}
Solid-state sintering has been used to prepare the perovskite $\mathrm{BaZr}_{0.9} \mathrm{Sc}_{0.1} \mathrm{O}_{3-\delta}$. Analysis of $\mathrm{X}$-ray powder diffraction data shows that an increase of the unit cell parameter, $a$, was observed after deuteration. Rietveld analysis of room-temperature neutron powder diffraction data confirmed cubic symmetry (space group $P m-3 m$ ). Dynamic thermogravimetric analysis indicates that the hydration process occurs below $335^{\circ} \mathrm{C}$ and approximately $58 \%$ of the theoretical number of protonic defects can be filled. The presence of protons/deutrons is seen from the strong $\mathrm{O}-\mathrm{H} / \mathrm{O}-\mathrm{D}$ stretch band in the infrared spectrum of the hydrated/deuterated samples. The proton conductivity of a prehydrated sample was investigated under dry and wet Ar atmospheres.
\end{abstract}

\section{Introduction}

E LECTROLYTE materials are generally ionic conductors and electronic insulators. Proton conducting electrolytes have a wide range of potential applications in fuel cells, batteries, sensors, electrolyzers, etc. ${ }^{1-3}$ Among these application fields, the most promising and time-relevant use of these materials is in fuel cells. For example, in low-temperature $\left(T<100^{\circ} \mathrm{C}\right)$ fuel cells such as a polymer electrolyte fuel cell (PEFC), Nafion (perfluorosulfonic polymer) is used as the electrolyte material, with the low operating temperatures necessitating the use of expensive platinum catalysts. Currently, high-temperature fuel cells based on oxide-ion conductors operate at $T>600^{\circ} \mathrm{C}$, which limits the wide range of material selectivity and also leads to slow start-up intervals. Therefore, a proton conducting fuel cell operating in the intermediate temperature range $\left(200^{\circ}-600^{\circ} \mathrm{C}\right)$ is a desirable alternative.

Successive investigation and literature data compiled by Norby ${ }^{2}$ show the presence of a "gap," within the intermediate temperature range, in which no materials show sufficiently high proton conductivity. Narrowing this gap would be very beneficial from a technological point of view. For $\mathrm{A}^{2+} \mathrm{B}^{4+} \mathrm{O}_{3}$-type perovskite oxides, Y-doped $\mathrm{BaZrO}_{3}$ and $\mathrm{BaCeO}_{3}$ show the highest proton conductivities. ${ }^{4-10}$ Different parameters, such as hydration enthalpy $(\Delta H)$, electronegativity, size of the dopant atoms, and crystal structure, have been used in order to understand the material conduction properties and predict new materials that may exhibit high conductivity. In $\mathrm{A}^{3+} \mathrm{B}^{3+} \mathrm{O}_{3}$-type

N.J. Dudney—contributing editor

Manuscript No. 23674. Received August 28, 2007; approved May 20, 2008.

This work was supported by the Swedish Research Council, and the National Graduate School in Material Science, "Solid state proton conductivity: structure, dynamics and simulation," at Chalmers University of Technology, Gothenburg, Sweden.

Author to whom correspondence should be addressed. e-mail: km01ahis@chalmers.se perovskite oxides, such as $\mathrm{La}_{0.9} \mathrm{Sr}_{0.1} \mathrm{MO}_{3-\delta}(\mathrm{M}=\mathrm{Sc}$, In, and $\mathrm{Lu})$, the highest proton conductivity was found in the Sc compound, ${ }^{11}$ i.e. in the materials with the smallest B-site cation. A different dependence was observed for the $\mathrm{A}^{2+} \mathrm{B}^{4+} \mathrm{O}_{3}$-type perovskite oxides of $\mathrm{BaZr}_{0.95} \mathrm{M}_{0.05} \mathrm{O}_{3-\delta}(\mathrm{M}=\mathrm{Y}$, Dy, In, Nd, and $\mathrm{Ga}){ }^{12}$ Here, it was reported that the proton conductivity increased with an increase in dopant B-site cation size up to an ionic radius of $\approx 0.9 \AA$ and when the ionic radius of the dopant ion exceeds $0.9 \AA$, the conductivity starts to decrease, for example for Nd. For complex perovskites, higher conductivity and lower activation energy are generally found when the difference in the ionic radius of the B-site cations is small. ${ }^{13}$ Indeed, the factors controlling the conduction process may be different for different types of perovskite oxides. In addition, enhanced conductivity is usually observed for A-site cations of higher ionic radius. ${ }^{5,12}$ In general, the sample having a higher crystal symmetry shows higher proton conductivity; this is especially true for zirconate systems.

In this study, $10 \mathrm{~mol} \%$ Sc-doped $\mathrm{Ba}^{2+} \mathrm{Zr}^{4+} \mathrm{O}_{3}$ was investigated. Proton diffusivity in this material has been investigated before at low temperatures, $T \leq 200^{\circ} \mathrm{C}$. ${ }^{14}$ In the present study, we have used a combination of different techniques: X-ray powder diffraction (XRPD), neutron powder diffraction (NPD), dynamic thermogravimetric analysis (TGA), infrared (IR) spectroscopy, and electrochemical measurements (impedance analysis). Deuterium-substituted samples have been used in the NPD experiments due to the high incoherent neutron scattering cross section of protons.

\section{Experimental Procedure}

Samples were prepared by a traditional solid-state sintering technique. Appropriate amounts of $\mathrm{BaCO}_{3}(99 \%), \mathrm{Sc}_{2} \mathrm{O}_{3}$ $(99.9 \%)$, and $\mathrm{ZrO}_{2}\left(<2 \% \mathrm{HfO}_{2}\right)$ have been mixed in order to obtain the desired compositions. The oxides were heated to $800^{\circ} \mathrm{C}$ overnight to remove moisture before weighing. To ensure thorough mixing, ethanol $(99.5 \%)$ was added during the milling, which was performed manually using an agate mortar and pestle. The finely ground material was fired at $1000^{\circ} \mathrm{C}$ for $8 \mathrm{~h}$ and subsequently ground and pelletized using a $13 \mathrm{~mm}$ diameter die under a pressure of $\approx 538 \mathrm{MPa}$ ( 8 tons). The pellets were sintered at $1200^{\circ} \mathrm{C}$ in air for $72 \mathrm{~h}$ and finally reground and compacted under similar conditions and refired at $1500^{\circ} \mathrm{C}$ for $48 \mathrm{~h}$. The amount of $\mathrm{Hf}$ in the sintered powder was investigated by inductively coupled-plasma (ICP) emission spectroscopy. The ICP result showed that $1 \mathrm{~mol} \%$ of $\mathrm{Hf}$ was present in the sintered powder and this value has been used as a starting value for Rietveld refinement, which is described in the discussion. After sintering at $1500^{\circ} \mathrm{C}$, the pellets showed a density corresponding to $\approx 70 \%$ of the theoretical value. A dried sample was prepared by annealing the as-prepared sample at $900^{\circ} \mathrm{C}$ in $\approx 10^{-6} \mathrm{mbar}$ 
pressure overnight. The hydration reaction was carried out at $300^{\circ} \mathrm{C}$ under a humid atmosphere $\left(\mathrm{N}_{2}\right.$ saturated with water vapor at $76.2^{\circ} \mathrm{C}$, i.e. $P\left(\mathrm{H}_{2} \mathrm{O}\right)=0.40 \mathrm{~atm}$.) for several days.

The XRPD measurements were carried out at ambient temperature using a Siemens D5000 powder diffractometer (BrukerAXS, Karlsruhe, Germany) $(\mathrm{CuK} \alpha=1.5418 \AA)$. For structural refinement, the XRPD data (in this case, a Bruker AXS D8 ADVANCE VARIO powder diffractometer, $\mathrm{CuK} \alpha 1=1.54058$ $\AA$, was used) were collected over a $2 \theta$ range of $15^{\circ}-120^{\circ}$ with a step size of $0.02^{\circ}$ and an acquisition time per step of $15 \mathrm{~s}$.

The TREOR ${ }^{15}$ program was used for indexing and evaluation of the lattice parameter. NPD data for dried and deuterated samples were collected at ambient temperature on a high-resolution D2B diffractometer with a $\lambda=1.5937 \AA$ (at the Institut Laue Langevin, Grenoble, France). The obtained data sets were refined by the Rietveld method ${ }^{16}$ using the GSAS $^{17}$ (for analysis of XRPD data) and Fullprof ${ }^{18}$ (for analysis of NPD data) software.

Dynamic TGA was carried out on a dried sample on heating from $65^{\circ}$ to $925^{\circ} \mathrm{C}$ as well as cooling from $925^{\circ}$ to $65^{\circ} \mathrm{C}$ with a Setaram TAG 16 using a rate of $1.5^{\circ} \mathrm{C} / \mathrm{min}$. The measurement was performed under a stream of $\mathrm{Ar}$ gas saturated with water vapor at $46^{\circ} \mathrm{C}\left(P\left(\mathrm{H}_{2} \mathrm{O}\right)=0.10 \mathrm{~atm}\right)$ with a flow rate of $20 \mathrm{~mL} / \mathrm{min}$.

The IR experiments were performed in an inert Ar atmosphere at room temperature in the diffuse reflectance mode using a Bruker VECTOR 22 FTIR spectrometer, equipped with a $\mathrm{KBr}$ beamsplitter, a deuterated triglycerine sulfate detector, and a diffuse reflectance device (Graseby Specac, "Selector"). A wrinkled aluminum foil was used as a reference. The vibrational spectra was derived by taking the logarithm of the ratio between the reference spectrum and the sample spectrum.

The impedance was measured from $1 \mathrm{MHz}$ to $1 \mathrm{~Hz}$ using a Solatron 1260 frequency response analyzer in the stand-alone mode. The sine wave amplitude was $1 \mathrm{~V}$ rms. The conductivity cell used was a ProboStat ${ }^{\mathrm{TM}}$ from Norwegian Electro Ceramics AS (NorECs). ${ }^{19}$ Approximately $0.3 \mathrm{~cm}^{2}$ of the oxide electrode surface was covered with a conducting platinum paste and a platinum grid to assure good ohmic contacts. The covered surface area was measured using an optical microscope. At first impedance measurements were performed for prehydrated samples on heating from $150^{\circ}$ to $900^{\circ} \mathrm{C}$ (heating cycle) and down from $900^{\circ}$ to $150^{\circ} \mathrm{C}$ (cooling cycle) under a dried Ar atmosphere at $50^{\circ} \mathrm{C}$ intervals and allowing $10 \mathrm{~min}$ to elapse at each new temperature before the impedance was recorded. In this case, the Ar gas was dried by flowing through two beds of $\mathrm{P}_{2} \mathrm{O}_{5}$. In order to limit any water uptake from the ambient atmospheres, two silica tubes were used to encase the cell as extra protection during the experiments. Wet runs were subsequently carried out with a porous $\mathrm{Al}_{2} \mathrm{O}_{3}$ outer tube on the same pellet under $\mathrm{Ar}$ saturated at $22^{\circ} \mathrm{C}$ with water, or heavy water vapor, $\left(P\left(\mathrm{H}_{2} \mathrm{O}\right)\right.$ or $\left.P\left(\mathrm{D}_{2} \mathrm{O}\right)=0.026 \mathrm{~atm}\right)$ on cooling from $900^{\circ}$ to $150^{\circ} \mathrm{C}$ in $50^{\circ} \mathrm{C}$ steps. After reaching the desired temperature, $1 \mathrm{~h}$ elapsed before the impedance spectra were recorded.

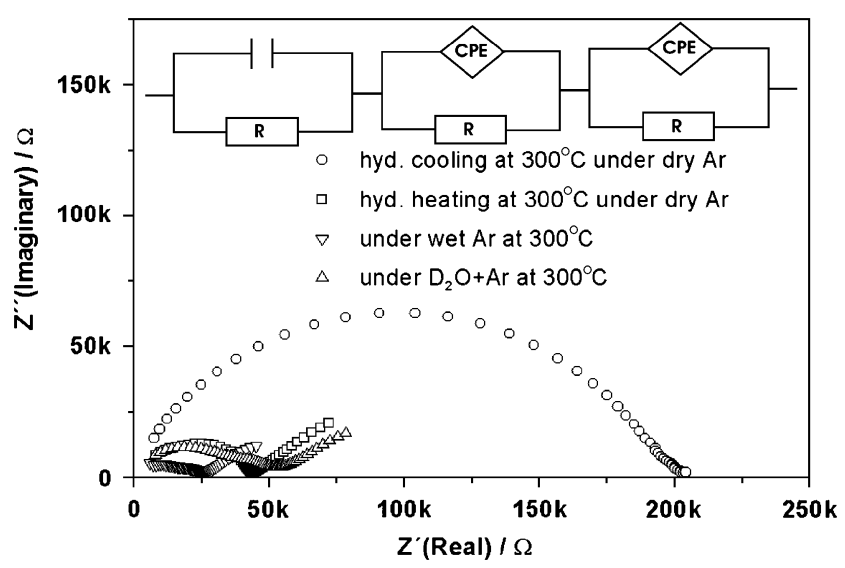

Fig. 1. Complex plane plot of $\mathrm{BaZr}_{0.9} \mathrm{Sc}_{0.1} \mathrm{O}_{3-\delta}$. Inset shows equivalent circuit used to extract the impedance data.

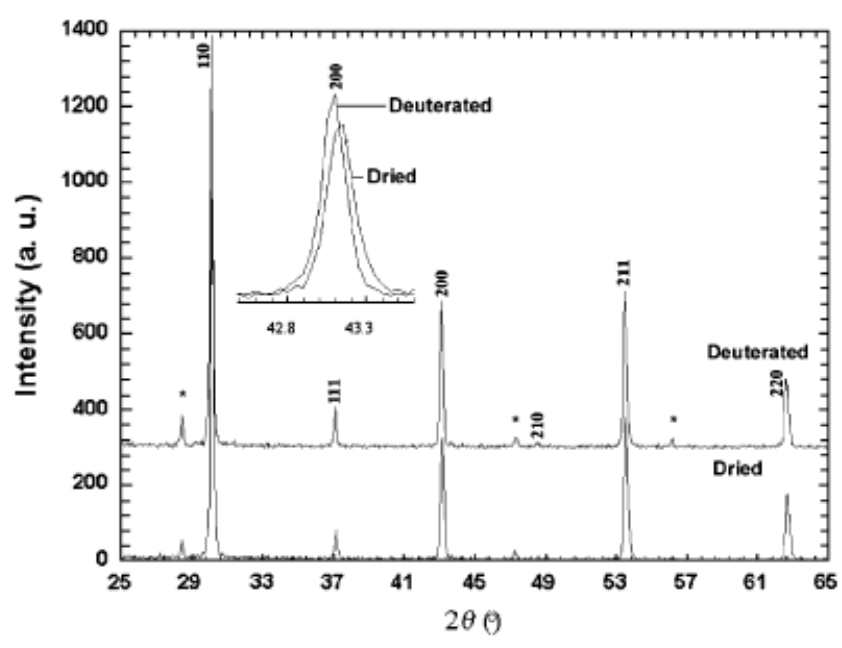

Fig. 2. X-ray diffraction patterns of dried and deuterated $\mathrm{BaZr}_{0.9} \mathrm{Sc}_{0.1} \mathrm{O}_{3-\delta}$. ${ }^{*}$ Represents the peaks due to silicon used as calibration standard. After deuteration the corresponding single peak shifts towards lower $2 \theta$ value (see the inset).

Two or three time constants were generally observed for all runs (except cooling cycle of the prehydrated sample under dry $\mathrm{Ar}$ ), corresponding to the bulk and grain boundary conduction. A typical complex plane plot is shown in Fig. 1, together with the equivalent circuit used in the data analysis. The obtained capacitance values were $\approx 10^{-11} \mathrm{Fcm}^{-2}$ for bulk conductivity and $\approx 10^{-9} \mathrm{Fcm}^{-2}$ for grain boundary conduction. Beyond $300^{\circ} \mathrm{C}$, it was difficult to separate the different conduction processes for all runs. Only one time constant was observed during the cooling cycle of the prehydrated sample and in this case one resistance - capacitance (RC) parallel equivalent circuit (constant phase elements [CPE] instead of a pure capacitor) was used to evaluate the impedance spectra.

\section{Results}

The room-temperature XRPD patterns of dried and deuterated $\mathrm{BaZr}_{0.9} \mathrm{Sc}_{0.1} \mathrm{O}_{3-\delta}$ are shown in Fig. 2. Indexing of these patterns clearly indicates that all samples possess cubic symmetry of space group $P m-3 m$. The unit-cell parameters $(a)$ have been determined from XRPD to be 4.1908(1) $\AA$ and 4.1946(4) $\AA$ for dried and deuterated samples, respectively. A similar value ( $a$ : 4.19276(6) А) was reported by Kreuer et al. ${ }^{14}$ Figure 3 plots the Rietveld fit achieved to XRD data for the as-prepared sample and Figs. 4 and 5 show the NPD data collected for dried

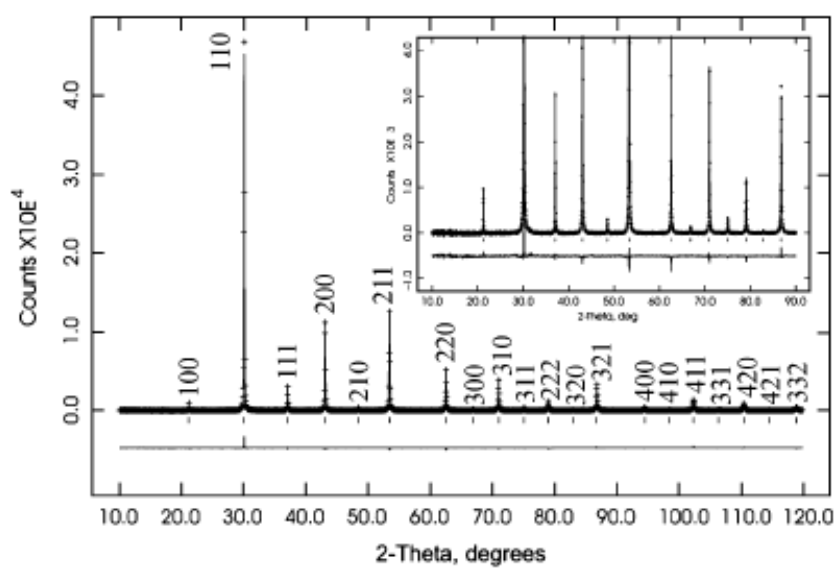

Fig. 3. Observed room temperature $\mathrm{X}$-ray powder diffraction profile of as-prepared $\mathrm{BaZr}_{0.891(2)} \mathrm{Hf}_{0.009(2)} \mathrm{Sc}_{0.1} \mathrm{O}_{2.95}$ (points), calculated pattern (solid line) and difference line (bottom). The tick marks show the positions of the Bragg peaks predicted by the structural model. Inset clearly shows no indication of impurities. 


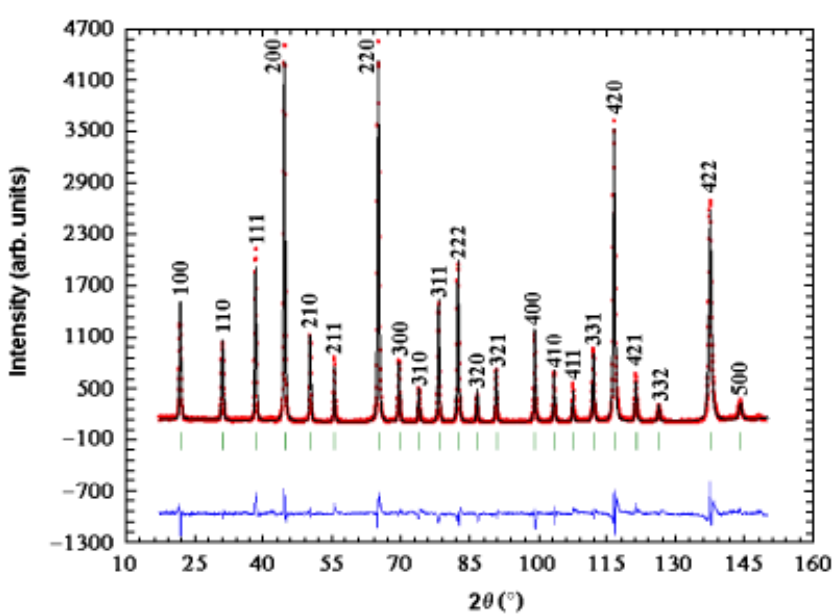

Fig. 4. Observed room temperature neutron powder diffraction profile of dried $\mathrm{BaZr}_{0.92(4)} \mathrm{Sc}_{0.08(4)} \mathrm{O}_{2.96(1)}$ (points), calculated pattern (solid line) and difference line (bottom). The tick marks show the positions of the Bragg peaks predicted by the structural model.

and deuterated samples, respectively. A summary of the information obtained from the Rietveld structural analyses is shown in Table I. We refined the fractional occupancy (both for XRPD and NPD data) of the A-site cation in order to check for the presence of any Ba deficiency that may have arisen from the high sintering temperature $\left(1500^{\circ} \mathrm{C}\right.$ for $\left.48 \mathrm{~h}\right)$. The refined A-site occupancy did not show any tendency to decrease from unity, i.e. values of 1.002(3) and 1.071(6) were obtained from the XRPD and NPD refinements, and therefore this value was set to 1.00. In contrast, the refinement of the B-site cations (fractional occupancies and isotropic atomic displacement parameter (IADP) for XRPD and NPD data) and oxygen occupancies and IADP (only for NPD data) converged rapidly, producing significant improvements to the quality of fit and chemically sensible values. The fractional occupancy and IADP of the oxygen site could not be obtained reliably from the XRPD data and consequently they were fixed to sensible values of 0.983 $\left(3 \times 0.983 \approx \mathrm{O}_{2.95}\right)$ and $2.5 \AA^{2}$, respectively.

According to our previous investigation ${ }^{20}$ of a closely related acceptor-doped perovskite, deuterium ions are found close to the oxygen site on the Wyckoff $12 h$ positions $(1 / 2,0.2,0)$ or possibly the $24 k$ positions $(0.54,0.21,0)$ within $P m-3 m$ symmetry. We used similar starting values for the analysis of the data from the deuterated $\mathrm{BaZr}_{0.9} \mathrm{Sc}_{0.1} \mathrm{O}_{3-\delta}$ sample in our attempts to locate deuterium ions within the structure. How-

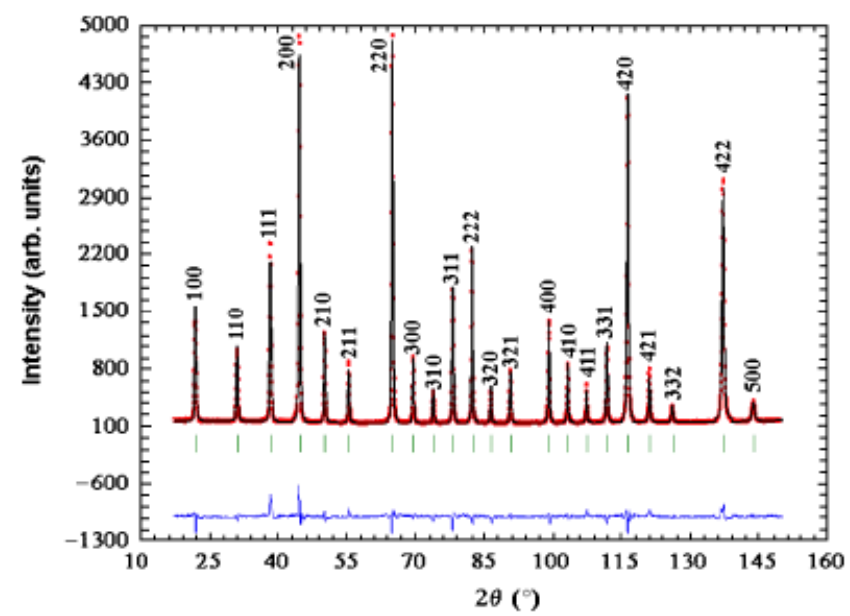

Fig. 5. Observed room temperature neutron powder diffraction profile of deuterated $\mathrm{BaZr}_{0.92(4)} \mathrm{Sc}_{0.08(4)} \mathrm{O}_{3.02(1)}$ (points), calculated pattern (solid line) and difference line (bottom). The tick marks show the positions of the Bragg peaks predicted by the structural model.
Table I. Summary Rietveld Analysis for $\mathrm{BaZr}_{0.9} \mathrm{Sc}_{0.1} \mathrm{O}_{3-\delta}$

\begin{tabular}{|c|c|c|c|}
\hline & $\begin{array}{l}\text { As-prepared } \\
\text { sample }^{\mathrm{a}}\end{array}$ & Dried sample ${ }^{\mathrm{b}}$ & $\begin{array}{l}\text { Deuterated } \\
\text { sample }^{\mathrm{b}}\end{array}$ \\
\hline Space group & $P m-3 m$ & $P m-3 m$ & $P m-3 m$ \\
\hline Lattice parameter & 4.1952 (1) $\AA$ & $4.1881(1) \AA$ & 4.1914 (1) $\AA$ \\
\hline \multicolumn{4}{|c|}{ Thermal parameter, $B$ iso $\left(\AA^{2}\right)$} \\
\hline $\begin{array}{l}\text { Ba at } 1 b 1 / 2, \\
1 / 2,1 / 2\end{array}$ & $2.72(2)$ & $0.71(3)$ & $0.81(3)$ \\
\hline $\mathrm{Zr}$ at $1 a 0,0,0$ & $2.12(2)$ & $0.75(2)$ & $0.79(2)$ \\
\hline Hf at $1 a 0,0,0$ & $2.12(2)$ & - & - \\
\hline Sc at $1 a 0,0,0$ & $2.12(2)$ & $0.75(2)$ & $0.79(2)$ \\
\hline $\mathrm{O}$ at $3 d 1 / 2,0,0$ & 2.5 & $1.03(2)$ & $1.01(2)$ \\
\hline \multicolumn{4}{|l|}{ Occupancies } \\
\hline $\mathrm{Ba}$ & 1.0 & 1.0 & 1.0 \\
\hline $\mathrm{Zr}$ & 0.891 (2) & 0.92 (4) & 0.92 (4) \\
\hline Hf & 0.009 (2) & - & - \\
\hline $\mathrm{Sc}$ & 0.10 & 0.08 (4) & 0.08 (4) \\
\hline $\mathrm{O}$ & 0.983 & $0.988(2)$ & $1.006(3)$ \\
\hline $\begin{array}{l}\text { Weighted } R \\
\text { factor( }(\%)\end{array}$ & 5.4 & 9.44 & 6.26 \\
\hline $\begin{array}{l}\text { Expected } R \\
\text { factor }(\%)\end{array}$ & 4.1 & 6.47 & 3.4 \\
\hline $\begin{array}{l}\text { No of fitted } \\
\text { parameters }\end{array}$ & 15 & 20 & 20 \\
\hline
\end{tabular}

Both $\mathrm{X}$-ray ${ }^{\mathrm{a}}$ and neutron ${ }^{\mathrm{b}}$ powder diffraction data were collected at ambient temperature.

ever, the refined deuterium position and site occupancy did not converge well enough to draw any definite conclusions.

Figure 6 shows the dynamic TGA result for the dried sample under a humid condition (10 vol\% water vapor). A change in mass was monitored during a heating and cooling run under a similar condition. During the heating cycle, mass gain occurred below $335^{\circ} \mathrm{C}$, while mass loss started beyond $335^{\circ} \mathrm{C}$. Above $800^{\circ} \mathrm{C}$, no mass change was observed. During the cooling cycle below $800^{\circ} \mathrm{C}$, the sample starts to gain mass under the same humid atmosphere. Finally, the sample regains its original mass approximately, which confirms the reversibility of the hydration process. The reversible mass loss/gain under a humid atmosphere was $\approx 0.19 \mathrm{wt} \%$, which suggests that approximately $58 \%$ of theoretically possible protonic defects $\left[\mathrm{OH}^{\bullet}\right]$ in $\mathrm{BaZr}_{0.9} \mathrm{Sc}_{0.1} \mathrm{O}_{3-\delta}$ were filled.

The infrared spectra of the hydrated, deuterated, and the dried samples are shown in Fig. 7. The spectrum of the hydrated sample shows a strong $\mathrm{O}-\mathrm{H}$ stretch band, $\sim 2500-3500 \mathrm{~cm}^{-1}$, typical of hydrated perovskites. ${ }^{5,21,22}$ This confirms the presence of dissolved protons into the perovskite structure of $\mathrm{BaZr}_{0.9} \mathrm{Sc}_{0.1} \mathrm{O}_{3-\delta}$ after hydration. Here, we also note that the spectrum of the dried sample contains a weak $\mathrm{O}-\mathrm{H}$ stretch band, which also indicates the presence of some protons in the dried samples although the

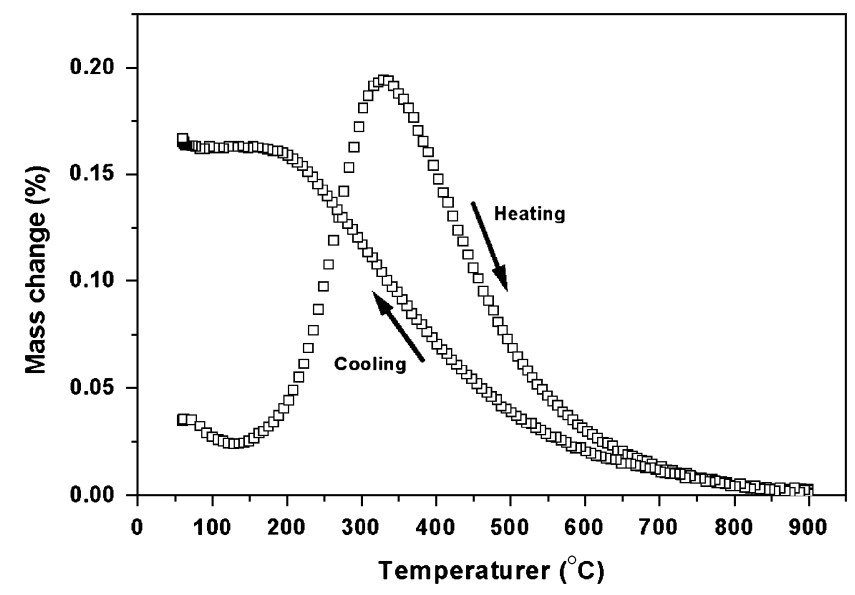

Fig. 6. Thermogravimetric analysis (TGA) curve for dried $\mathrm{BaZr}_{0.9} \mathrm{Sc}_{0.1} \mathrm{O}_{3-\delta}$ sample collected under humid atmosphere. 


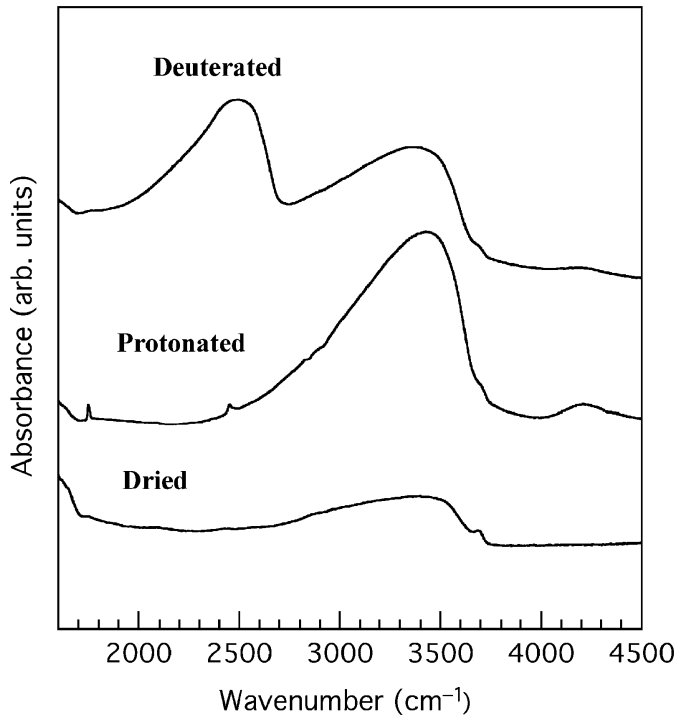

Fig. 7. Infrared absorbance spectra of dried, protonated and deuterated samples of $\mathrm{BaZr}_{0.9} \mathrm{Sc}_{0.1} \mathrm{O}_{3-\delta}$.

amount is considerably smaller than in the hydrated sample. For the deuterated sample, the spectrum shows the presence of both deuterons and protons in the structure as the band between 2000 and $2500 \mathrm{~cm}^{-1}$ is related to O-D stretches.

Figure 8 shows the Arrhenius plots of conductivity for the prehydrated sample under dry and wet Ar atmospheres. The conductivity values obtained at different temperatures are summarized in Table II. The total conductivity values of the prehydrated sample during heating and under wet $\mathrm{Ar}\left(\mathrm{Ar}+\mathrm{H}_{2} \mathrm{O}\right.$ and $\mathrm{Ar}+\mathrm{D}_{2} \mathrm{O}$ ) runs were nearly one order of magnitude higher compared with that of the cooling cycle at $300^{\circ} \mathrm{C}$. In contrast, at higher temperatures, e.g. $T>600^{\circ} \mathrm{C}$, these values are similar. The total conductivity measured under a heavy water $\left(D_{2} \mathrm{O}+\mathrm{Ar}\right)$ atmosphere was lower (Fig. 8) compared with under a water $\left(\mathrm{H}_{2} \mathrm{O}+\mathrm{Ar}\right)$ atmosphere in the temperature range $150^{\circ}-800^{\circ} \mathrm{C}$.

\section{Discussion}

Rietveld analysis of both the NPD and long scan (15.5 h) XRPD data did not show any indication of extra peaks arising from impurities such as $\mathrm{Sc}_{2} \mathrm{O}_{3}$ or $\mathrm{ZrO}_{2}$ that may have pointed toward $\mathrm{Ba}$ deficiency (see inset of Fig. 3). Furthermore, refinement of the A site occupancy factor favored full occupancy. Some authors $^{23-25}$ have reported that $\mathrm{BaO}$ evaporation occurs due to prolonged high-temperature synthesis. This $\mathrm{BaO}$ evaporation

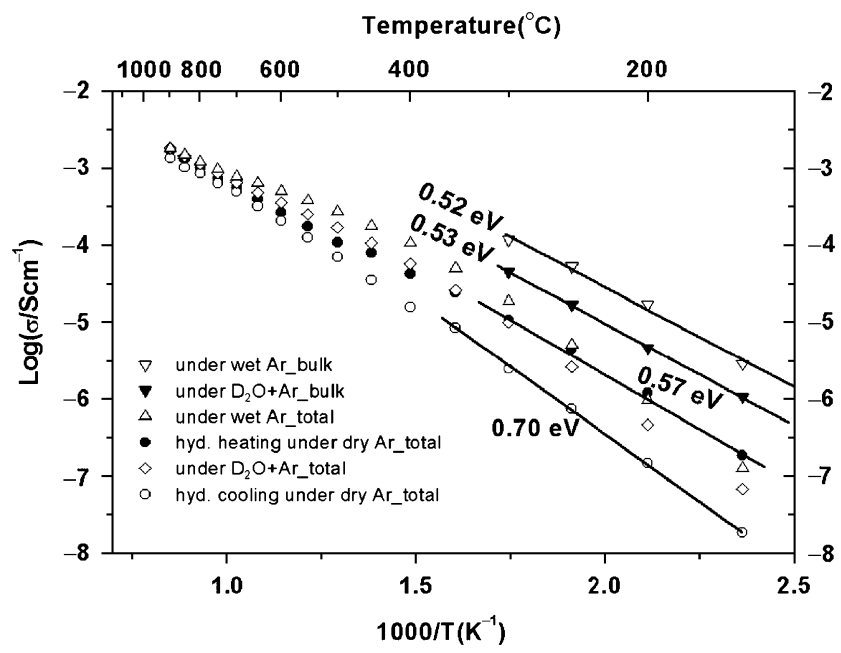

Fig. 8. Arrhenius plots of the conductivity of a $\mathrm{BaZr}_{0.9} \mathrm{Sc}_{0.1} \mathrm{O}_{3-\delta}$ sample under different experimental conditions. probably differs from system to system based on the exact composition and thermal history of the sample.

The ICP measurement showed the presence of $1 \mathrm{~mol} \% \mathrm{Hf}$ in an as-sintered sample, and hence the refinement (X-ray diffraction) was made on the basis of $\mathrm{Hf}$ in the structure model. In order to refine the occupancies of $\mathrm{Zr}$ and $\mathrm{Hf}$ on the $\mathrm{B}$ site, the value of Sc was set to 0.1 . The refinement converged slightly and the obtained value of $\mathrm{Hf}$ was $0.009(2)$, which is in excellent agreement with the ICP result. Because of similar coherent neutron scattering lengths of $\mathrm{Hf}(7.7 \mathrm{fm})$ and $\mathrm{Zr}(7.16 \mathrm{fm})$, the $\mathrm{Hf}$ and $\mathrm{Zr}$ contents were not verified for the dried and deuterated samples.

After the deuteration reaction, the corresponding Bragg peaks in the XRPD scans shift toward lower $2 \theta$ values (higher $d$-spacing) compared with the dried sample. This behavior is unambiguously shown in the inset of Fig. 2 and clearly indicates that the unit cell parameter of the deuterated sample was larger compared with the dried sample. An expansion of the unit cell is often observed after hydration/deuteration. ${ }^{20,26-29}$ This expansion of the unit cell parameter is a result of filling of oxygen vacancies $\left(V_{\mathrm{O}}^{\bullet \bullet}\right)$ by hydroxyl groups $\left(\mathrm{OH}_{\mathrm{O}}^{\bullet} / \mathrm{OD}_{\mathrm{O}}^{\bullet}\right)$ in the presence of water or heavy water vapor according to the following reaction:

$$
\mathrm{D}_{2} \mathrm{O} / \mathrm{H}_{2} \mathrm{O}(\mathrm{g})+\mathrm{O}_{\mathrm{O}}^{\times}+V_{\mathrm{O}}^{\bullet \bullet} \leftrightarrow 2 \mathrm{OD}_{\mathrm{O}}^{\bullet} / 2 \mathrm{OH}_{\mathrm{O}}^{\bullet}
$$

Rietveld analysis (Table I) of the NPD data confirms the cubic crystal symmetry and space group for both dried and deuterated samples. An expansion of the unit cell of the deuterated sample was also confirmed from the Rietveld analyses. In order to improve the electrical conductivity of the sample, charge-compensating oxygen vacancies $\left(V_{\mathrm{O}}^{\bullet \bullet}\right)$ were created by partial substitution of trivalent $\mathrm{Sc}$ for tetravalent $\mathrm{Zr}$ ions. Charge balance calculations based on the idealized stoichiometry of $\mathrm{BaZr}_{0.9} \mathrm{Sc}_{0.1} \mathrm{O}_{3-\delta}$ indicate that a maximum of 0.05 moles of oxygen vacancy $\left(V_{\mathrm{O}}^{\bullet \bullet}\right)$ "per chemical formula" can be formed in the dried sample. Our refined oxygen content from the NPD data analysis for the dried sample showed that 0.04(1) moles of $V_{\mathrm{O}}^{\bullet \bullet}$ were in fact obtained, confirming that charge compensation occurred via vacancy formation. In an oxidizing atmosphere, charge compensation may instead occur through the formation of electronic holes as reported elsewhere. ${ }^{30-32}$ The oxygen content refined for the deuterated sample was $\mathrm{O}_{3.02(1)}$, i.e. the oxygen vacancies were, as expected, filled by $\mathrm{O}-\mathrm{D}$ groups according to reaction 1 . Hence, the refined oxygen levels for both samples were in good agreement with expected values of $\mathrm{O}_{2.95}$ and $\mathrm{O}_{3.00}$ for dried and deuterated samples, respectively.

The deuterium positions were not successfully located within the structure of the deuterated sample. For a $10 \mathrm{~mol} \% \mathrm{Sc}^{3+}$. substituted $\mathrm{BaZrO}_{3}$ sample, full occupation of the oxygen sites, and corresponding incorporation of twice as many deuterium (D) ions, would lead to a maximum of only $0.1 \mathrm{~mol} \mathrm{D} / \mathrm{mol}$ of $\mathrm{BaZr}_{0.9} \mathrm{Sc}_{0.1} \mathrm{O}_{2.95}$. At such low deuterium concentrations, it is quite difficult to locate their position reliably. Moreover, at ambient temperatures, the deuterium ions rotate around the oxide ions and are not fixed at one position. ${ }^{33}$ As suggested by Knight, ${ }^{34}$ a higher doping, which corresponds to a higher concentration of $\mathrm{D}$ in the structure, is required to obtain accurate refinement of deuterium positions, thermal parameters, and site occupancies. However, utilization of high-resolution NPD data collected at a low temperature can also be valuable. This is an approach that has already been successfully used to locate D sites for deuterated $\mathrm{BaZr}_{0.5} \mathrm{In}_{0.5} \mathrm{O}_{3-y}$ at $5 \mathrm{~K}$ by Ahmed et al., ${ }^{20}$ $\mathrm{SrZr}_{0.95} \mathrm{Sc}_{0.05} \mathrm{O}_{3-\alpha}$ at $10 \mathrm{~K}$ by Ito et al., ${ }^{35}$ and for protonated $\mathrm{BaCe}_{0.9} \mathrm{Y}_{0.1} \mathrm{O}_{2.95}$ at $4.2 \mathrm{~K}$ by Knight. ${ }^{34}$

The result of the dynamic TGA shows that the content of protons in the title compound was less $(58 \%$ of the theoretical value) compared with for example, $10 \mathrm{~mol} \%$ Yb-doped $(74 \%$ of the theoretical value) ${ }^{36}$ under identical conditions. In order to explain this result, the enthalpy of the hydration reaction (Eq. (1)) $\Delta H$ was calculated using the equation reported by Norby et al. ${ }^{37}$ where, 
Table II. Summary of Conductivity Results for $\mathrm{BaZr}_{0.9} \mathrm{Sc}_{0.1} \mathrm{O}_{3-\delta}$

\begin{tabular}{|c|c|c|c|}
\hline Sample type & $\begin{array}{c}\sigma \text { at } 300^{\circ} \mathrm{C} \\
\left(\mathrm{Scm}^{-1}\right)\end{array}$ & $\begin{array}{c}\sigma \text { at } 600^{\circ} \mathrm{C} \\
\left(\mathrm{Scm}^{-1}\right)\end{array}$ & $\begin{array}{c}\sigma \text { at } 900^{\circ} \mathrm{C} \\
\left(\mathrm{Scm}^{-1}\right)\end{array}$ \\
\hline $\begin{array}{l}\text { Prehydrated } \\
\text { (heating cycle) }\end{array}$ & $\begin{array}{l}1.1 \times 10^{-5} \\
\quad \text { total })\end{array}$ & $\begin{array}{l}2.7 \times 10^{-4} \\
\quad(\text { total })\end{array}$ & $\begin{array}{l}1.7 \times 10^{-3} \\
\text { (total) }\end{array}$ \\
\hline $\begin{array}{l}\text { Prehydrated } \\
\text { (cooling cycle) }\end{array}$ & $\begin{array}{l}2.5 \times 10^{-6} \\
\quad(\text { total })\end{array}$ & $\begin{array}{l}2.1 \times 10^{-4} \\
\quad(\text { total })\end{array}$ & $\begin{array}{l}1.3 \times 10^{-3} \\
(\text { total })\end{array}$ \\
\hline Under wet Ar & $\begin{array}{l}1.9 \times 10^{-5} \\
\quad(\text { total }) \\
1.2 \times 10^{-4} \\
\quad(\text { bulk })\end{array}$ & $\begin{array}{l}5.0 \times 10^{-4} \\
\quad(\text { total })\end{array}$ & $\begin{array}{c}1.8 \times 10^{-3} \\
(\text { total })\end{array}$ \\
\hline $\begin{array}{l}\text { Under } \\
\mathrm{D}_{2} \mathrm{O}+\mathrm{Ar}\end{array}$ & $\begin{array}{l}9.8 \times 10^{-6} \\
\quad(\text { total }) \\
4.5 \times 10^{-5} \\
\quad(\text { bulk })\end{array}$ & $\begin{array}{l}3.5 \times 10^{-4} \\
\quad(\text { total })\end{array}$ & $\begin{array}{c}1.8 \times 10^{-3} \\
(\text { total })\end{array}$ \\
\hline
\end{tabular}

$$
\Delta H\left(\mathrm{kJmol}^{-1}\right)=400 \Delta X_{\mathrm{B}-\mathrm{A}}-180
$$

Here, $\Delta X_{\mathrm{B}-\mathrm{A}}$ is the difference in electronegativity between the cations residing in the $\mathrm{B}$ site and $\mathrm{A}$ site of the perovskite. AllredRochow electronegativities ${ }^{38}$ were used to determine $\Delta X_{\mathrm{B}-\mathrm{A}}$. The calculated hydration enthalpies $(\Delta H)$ were -80.8 and -86.4 $\mathrm{kJmol}^{-1}$ for $\mathrm{Sc}$ and $\mathrm{Yb}$ samples, respectively. For materials showing a more negative $\Delta H$, both the content of protons and the dehydration temperature are expected to be higher, ${ }^{5,39}$ which is in line with our experimental TGA results. Besides hydration enthalpy $(\Delta H)$, other factors such as structural disorder and microstructure may influence the degree of hydration.

From the IR spectra of the dried sample in Fig. 7, it is evident that although the drying procedure was performed at $900^{\circ} \mathrm{C}$ under vacuum, it seems very difficult to remove all protons from the structure. Perhaps such strongly bound protons located in grain boundaries or other extreme structural configurations in the material. This could explain why we do not find any evidence for deuterons from the NPD refinement. In addition, it should be noted that the sensitivity for detecting protons with infrared spectroscopy is much higher than with NPD.

The total conductivity of the pre-hydrated sample (Fig. 8) recorded at $T \leq 350^{\circ} \mathrm{C}$ during the heating cycle shows an increase by nearly one order of magnitude in comparison with the same temperature region for the cooling cycle. At temperatures above $600^{\circ} \mathrm{C}$, the conductivity values are similar for both cycles. The higher value of conductivity obtained in the intermediate temperature range $\left(150^{\circ}-600^{\circ} \mathrm{C}\right)$ for the heating cycle reflects the presence of a significant level of protons within the sample. With increasing temperature, the protons start to leave the sample and at $T>600^{\circ} \mathrm{C}$, the majority of protons would have left. These conductivity results can be correlated to the TGA results (Fig. 6), which clearly indicate a mass gain on heating the dried sample under a wet atmosphere starting at approximately $200^{\circ} \mathrm{C}$ and a mass loss on the same sample starting at approximately $>350^{\circ} \mathrm{C}$. Beyond $600^{\circ} \mathrm{C}$, very little mass loss is observed, indicating that most of the protons have left the sample. This is consistent with the much lower conductivity values obtained below $600^{\circ} \mathrm{C}$ during the cooling cycle for the now effectively dehydrated sample. Because the conductivity experiment was performed in an inert, dry, atmosphere unlike the TGA, further proton uptake from the atmosphere was strictly limited. Analogous behavior has been reported previously for many systems. $26,27,36,40,41$

The conductivity (Fig. 8) of the same sample under wet Ar shows a significantly higher value compared with the heating cycle under dry Ar, especially in the temperature range $300^{\circ}$ $700^{\circ} \mathrm{C}$. In the prehydrated sample, protons readily leave the sample at elevated temperatures and further uptake is not possible from the controlled dry atmosphere. Under wet Ar, further proton uptake is easily possible at these temperatures as the kinetics of the water uptake reaction is believed to be fast. ${ }^{42}$ However, the difference in conductivity becomes smaller at temperatures $>800^{\circ} \mathrm{C}$. At such high temperatures, the protonic defects are unstable in the material; hence, protons are not the dominating charge carriers. Possibly oxide-ion or hole conduction dominates in the high-temperature range.

Lower conductivity (Fig. 8) under heavy water $\left(\mathrm{D}_{2} \mathrm{O}+\mathrm{Ar}\right)$ compared with under water $\left(\mathrm{H}_{2} \mathrm{O}+\mathrm{Ar}\right)$ in the temperature range $150^{\circ}-600^{\circ} \mathrm{C}$ in fact shows the isotope effect, which, in principle, confirms that the material is a proton conductor. The classical isotope effect expected for the conductivity measurement is that $\sigma_{\mathrm{H}} / \sigma_{\mathrm{D}} \approx \sqrt{ } 2$. In this study, the ratio $\sigma_{\mathrm{H}} / \sigma_{\mathrm{D}}$ (for bulk) was $\approx 2.5-3$ and $\sigma_{\mathrm{H}} / \sigma_{\mathrm{D}}$ (for total) was $\approx 1.4-2$. Survey of conductivity results on other perovskite oxides reveals that similar values were also reported by Nowick and Vaysleyb. ${ }^{43}$

From Fig. 8, it is apparent that somewhat higher activation energies were obtained compared with the typical values of $\sim 0.4-0.5 \mathrm{eV}$ found for the best proton conductors such as $\mathrm{Y}$ doped $\mathrm{BaZrO}_{3}$ and $\mathrm{BaCeO}_{3}{ }^{5,12,39}$ Islam et al. ${ }^{44}$ calculated that the binding energies of hydroxy-dopant pairs $\left(\mathrm{OH}_{\mathrm{O}}^{\bullet} \mathrm{M}_{\mathrm{Zr}}^{\prime}\right)$ were $-0.74 \mathrm{eV}$ and $-0.26 \mathrm{eV}$, for $\mathrm{M}=\mathrm{Sc}$ and $\mathrm{Y}$, respectively. In addition, higher interaction energies $\left(\Delta E^{\text {int }}\right)$ for dopant-proton clusters in $\mathrm{BaZrO}_{3}$ were reported for the case of a Sc dopant compared with a Y dopant. ${ }^{45}$ According to recent first principle investigations of $\mathrm{BaZrO}_{3}$ by Björketun et al., ${ }^{46}$ it was found that the dopants act as "trapping" centers for migrating protons. This trapping region was strongly correlated with dopant radius. Our experimental findings show good agreement with theoretical work, confirming a higher activation energy and lower proton mobility for Sc-doped $\mathrm{BaZrO}_{3}$. Similar experimental results for the temperature interval below $200^{\circ} \mathrm{C}$ have also been reported by Kreuer et al. ${ }^{14}$

\section{Conclusions}

Using a standard solid-state synthesis route, it was possible to obtain single-phase $\mathrm{BaZr}_{0.9} \mathrm{Sc}_{0.1} \mathrm{O}_{3-\delta}$ samples. Analysis of XRPD and NPD data indicates that the structure of all the samples show cubic symmetry (space group $P m-3 m$ ). Dynamic TGA data showed that nearly $58 \%$ of the theoretical number of protonic defects can be filled upon hydration. IR spectra clearly show the presence of a significant number of protons in the hydrated sample compared with the dried sample. Proton conduction in this material was mainly dominating in the temperature range $\left(150^{\circ}-600^{\circ} \mathrm{C}\right)$. The lower proton conductivity and higher activation energy reflect a strong association between the proton and the Sc-dopant ions, in agreement with several theoretical studies.

\section{Acknowledgments}

The authors gratefully acknowledge professor L.-G. Johansson and Dr. H. Götlind for their continuous support with Thermogravimetry experiments as well as Dr. P. F. Henry for helping us to collect neutron data at the ILL, Grenoble, France.

\section{References}

${ }^{1}$ H. Iwahara, "Technological Challenges in the Application of Proton Conducting Ceramics," Solid State Ion., 77, 289-98 (1995).

${ }^{2}$ T. Norby, "Solid-State Protonic Conductors: Principles, Properties, Progress and Prospects," Solid State Ion., 125, 1-11 (1999).

${ }^{3} \mathrm{Ph}$. Colomban (Ed), Proton Conductors: Solids, Membranes and Gels-Materials and Devices. Cambridge University Press, Cambridge, 1992.

${ }^{4}$ H. Iwahara, H. Uchida, K. Ono, and K. Ogaki, "Proton Conduction in Sintered Oxides Based on $\mathrm{BaCeO}_{3}$, , J. Electrochem. Soc., 135, 529-33 (1988).

${ }^{5}$ K. D. Kreuer, "Aspects of the Formation and Mobility of Protonic Charge Carriers and the Stability of Perovskite-Type Oxides," Solid State Ion., 125, 285302 (1999).

${ }^{6}$ T. Schober and H. G. Bohn, "Water Vapor Solubility and Electrochemical Characterization of the High Temperature Proton Conductor $\mathrm{BaZr}_{0.9} \mathrm{Y}_{0.1} \mathrm{O}_{2.95}$," Solid State Ion., 127, 351-60 (2000). 
${ }^{7}$ K. Katahira, Y. Kohchi, T. Shimura, and H. Iwahara, "Protonic Conduction in Zr-Substituted $\mathrm{BaCeO}_{3}$," Solid State Ion., 138, 91-8 (2000).

${ }^{8}$ K. D. Kreuer, "Proton-Conducting Oxides," Annu. Rev. Mater. Res., 33, 333 59 (2003).

${ }^{9}$ P. Babilo and S. M. Haile, "Enhanced Sintering of Yttrium-Doped Barium Zirconate by Addition of ZnO,” J. Am. Ceram. Soc., 88, 2362-8 (2005).

${ }^{10} \mathrm{~K}$. Nomura and H. Kageyama, "Transport Properties of $\mathrm{Ba}\left(\mathrm{Zr}_{0.8} \mathrm{Y}_{0.2}\right) \mathrm{O}_{3-\delta}$ Perovskite," Solid State Ion., 178, 661-5 (2007).

${ }^{11}$ K. Nomura, T. Takeuchi, S. Tanase, H. Kageyama, K. Tanimoto, and Y. Miyazaki, "Proton Conduction in $\left(\mathrm{La}_{0.9} \mathrm{Sr}_{0.1}\right) \mathrm{M}^{\mathrm{III}} \mathrm{O}_{3-\delta}\left(\mathrm{M}^{\mathrm{III}}=\mathrm{Sc}\right.$, In, and Lu) Perovskites," Solid State Ion., 154-155, 647-52 (2002).

${ }^{12}$ H. Iwahara, T. Yajima, T. Hibino, K. Ozaki, and H. Suzuki, "Protonic Conduction in Calcium, Strontium and Barium Zirconates," Solid State Ion., 61, 65-9 (1993)

${ }^{13}$ A. S. Nowick, Y. Du, and K. C. Liang, "Some Factors that Determine Proton Conductivity in Non Stoichiometric Complex Perovskites," Solid State Ion., 125, 303-11 (1999).

${ }^{14}$ K. D. Kreuer, St. Adams, W. Munch, A. Fuchs, U. Klock, and J. Maier, "Proton Conducting Alkaline Earth Zirconates and Titanates for High Drain Electrochemical Applications," Solid State Ion., 145, 295-306 (2001).

${ }^{15}$ P. E. Werner, L. Eriksson, and M. Westdahl, "TREOR, A Semi-Exhaustive Trial-and-Error Powder Indexing Program for all Symmetries," J. Appl. Crystallogr., 18, 367-70 (1985).

${ }^{16}$ H. M. Rietveld, "A Profile Refinement Method for Nuclear and Magnetic Structures," J. Appl. Crystallogr., 2, 65-71 (1969).

${ }^{17}$ A. C. Larson and R. B. Von Dreele, General Structure Analysis System, LAUR 86-748. Los Alamos National Lab, Los Alamos, 1994.

${ }^{18}$ J. R. Carvajal, "Recent Advances in Magnetic Structure Determination by Neutron Powder Diffraction," Physica B, 192, 55-69 (1993).

${ }^{19}$ NorECs, "Norwegian Electro Ceramics AS," (www.norecs.com).

${ }^{20}$ I. Ahmed, C. S. Knee, M. Karlsson, S.-G. Eriksson, P. F. Henry, A. Matic, D. Engberg, and L. Börjesson, "Location of Deuteron Sites in the Proton Conducting Perovskite $\mathrm{BaZr}_{0.50} \mathrm{In}_{0.50} \mathrm{O}_{3-y}$," J. Alloys Comp., 450, 103-10 (2008).

${ }^{21}$ M. Karlsson, M. E. Björketun, P. G. Sundell, A. Matic, G. Wahnström, D. Engberg, L. Börjesson, I. Ahmed, S.-G. Eriksson, and P. Berastegui, "Vibrational Properties of Protons in Hydrated $\mathrm{BaZr}_{1-x} \mathrm{In}_{x} \mathrm{O}_{3-x / 2}$," Phys. Rev. B, 72, 094303-1-7 (2005).

${ }^{22}$ T. Omata, M. Takagi, and S. O.-Y. Matsuo, "O-H Stretching Vibrations of Proton Conducting Alkaline-Earth-Zirconates," Solid State Ion., 168, 99-109 (2004).

${ }^{23} \mathrm{~A}$. Magrez and T. Schober, "Preparation, Sintering, and Water Incorporation of Proton Conducting $\mathrm{Ba}_{0.99} \mathrm{Zr}_{0.8} \mathrm{Y}_{0.2} \mathrm{O}_{3-\delta}$ : Comparison between Three Different Synthesis Techniques," Solid State Ion., 175, 585-8 (2004).

${ }^{24}$ E. Kendrick, K. S. Knight, M. S. Islam, and P. R. Slater, "Structural Studies of the Proton Conducting Perovskite $\mathrm{La}_{0.6} \mathrm{Ba}_{0.4} \mathrm{ScO}_{2.8}$," Solid State Ion., 178, 943 9 (2007)

${ }^{25}$ J. Wu, L. P. Li, W. T. P. Espinosa, and S. M. Haile, "Defect Chemistry and Transport Properties of $\mathrm{Ba}_{x} \mathrm{Ce}_{0.85} \mathrm{M}_{0.15} \mathrm{O}_{3-\delta}$," J. Mater. Res., 19, 2366-76 (2004).

${ }^{26}$ I. Ahmed, S.-G. Eriksson, E. Ahlberg, C. S. Knee, P. Berastegui, L.-G. Johansson, H. Rundlöf, M. Karlsson, A. Matic, L. Börjesson, and D. Engberg, "Synthesis and Structural Characterization of Perovskite type Proton Conducting $\mathrm{BaZr}_{1-x} \mathrm{In}_{x} \mathrm{O}_{3-\delta}(0.0 \leq x \leq 0.75)$," Solid State Ion., 177, 1395- 403 (2006).

${ }^{27}$ I. Ahmed, S.-G. Eriksson, E. Ahlberg, C. S. Knee, M. Karlsson, A. Matic, D. Engberg, and L. Börjesson, "Proton Conductivity and Low Temperature Structure of In-Doped $\mathrm{BaZrO}_{3}$," Solid State Ion., 177, 2357-62 (2006).
${ }^{28}$ D. J. D. Corcoran and J. T. S. Irvine, "Investigations into $\mathrm{Sr}_{3} \mathrm{CaZr}_{0.5-}$ $\mathrm{Ta}_{1.5} \mathrm{O}_{8.75}$, a Novel Proton Conducting Perovskite Oxide," Solid State Ion., 145, 307-13 (2001)

${ }^{29}$ I. Sosnowska, R. Przenioslo, W. Schäfer, W. Kockelmann, R. Hempelmann, and K. Wysocki, "Possible Deuterium Positions in the High-Temperature Deuterated Proton Conductor $\mathrm{Ba}_{3} \mathrm{Ca}_{1+y} \mathrm{Nb}_{2-y} \mathrm{O}_{9-\delta}$ Studied by Neutron and X-Ray Powder Diffraction," J. Alloys Comp., 328, 226-30 (2001).

${ }^{30}$ N. Bonanos, "Transport Properties and Conduction Mechanism in HighTemperature Protonic Conductors," Solid State Ion., 53-56, 967-74 (1992).

${ }^{31}$ K. D. Kreuer, "On the Development of Proton Conducting Materials for Technological Applications," Solid State Ion., 97, 1-15 (1997).

${ }^{32}$ T. He, K. D. Kreuer, Y. M. Baikov, and J. Maier, "On the Transport Properties of a Proton Conducting Ca-Doped $\mathrm{Ba}_{3}\left(\mathrm{CaNb}_{2}\right) \mathrm{O}_{9}$ Single Crystal," Proceedings-Electrochemical Society (Solid Oxide Fuel Cells V), 97-40, 1057-65 (1997), ISSN:0161-6374.

${ }^{33}$ R. Hempelmann, M. Soetratmo, O. Hartmann, and R. Wäppling, "Muon Diffusion and Trapping in Proton Conducting Oxides," Solid State Ion., 107, 26980 (1998).

${ }^{34}$ K. S. Knight, "Powder Neutron Diffraction Studies of $\mathrm{BaCe}_{0.9} \mathrm{Y}_{0.1} \mathrm{O}_{2.95}$ and $\mathrm{BaCeO}_{3}$ at $4.2 \mathrm{~K}$ : A Possible Structural Site for the Proton," Solid State Ion., 127, 43-8 (2000).

${ }^{35}$ T. Ito, T. Nagasaki, K. Iwasaki, M. Yoshino, T. Matsui, N. Igawa, and Y. Ishii, "The Determination of Deuteron Site in $\mathrm{SrZr}_{0.95} \mathrm{Sc}_{0.05} \mathrm{O}_{3-\alpha}$ by Neutron Powder Diffraction," Solid State Ion., 177, 2353-6 (2006).

${ }^{36}$ I. Ahmed, S.-G. Eriksson, E. Ahlberg, C. S. Knee, H. Götlind, L.-G. Johansson, M. Karlsson, A. Matic, and L. Börjesson, "Structural Study and Proton Conductivity in Yb-Doped $\mathrm{BaZrO}_{3}$," Solid State Ion., 178, 515-20 (2007).

${ }^{37}$ T. Norby, M. Wideroe, R. Glöckner, and Y. Larring, "Hydrogen in Oxides," Dalton Trans., 19, 3012-8 (2004).

${ }^{38}$ C. K. Jorgensen and K. D. Sen, "Electronegativity”. Springer-Verlag, New York, 1987, LLC, ISBN: 0-387-17740-x.

${ }^{39}$ R. Glöckner "Dissolution and Transport of Protons in Some PerovskiteRelated Oxides" Ph.D Thesis (2000), ISSN 1501-7710.

${ }^{40}$ A. Manthiram, J. F. Kuo, and J. B. Goodenough, "Characterization of Oxygen-Deficient Perovskites as Oxide-Ion Electrolytes," Solid State Ion., 62, 225-34 (1993).

${ }^{41}$ I. Ahmed, E. Ahlberg, S.-G. Eriksson, C. S. Knee, M. Karlsson, A. Matic, and L. Börjesson, "Structural Study and Conductivity $\mathrm{BaZr}_{0.90} \mathrm{Ga}_{0.10} \mathrm{O}_{2.95}$," Ceram. Eng. Sci. Proc., 27, 105-17 (2006).

${ }^{42}$ K. D. Kreuer, E. Schönherr, and J. Maier, "Proton and Oxygen Diffusion in $\mathrm{BaCeO}_{3}$ Based Compounds: A Combined Thermal Gravimetric Analysis and Conductivity Study," Solid State Ion., 70-71, 278-84 (1994).

${ }^{43}$ A. S. Nowick and A. V. Vaysleyb, "Isotope Effect and Proton Hopping in High-Temperature Protonic Conductors," Solid State Ion., 97, 17-26 (1997).

${ }^{44}$ M. S. Islam, P. R. Slater, J. R. Tolchard, and T. Dinges, "Doping and Defect Association in $\mathrm{AZrO}_{3}(\mathrm{~A}=\mathrm{Ca}, \mathrm{Ba})$ and $\mathrm{LaMO}_{3}(\mathrm{M}=\mathrm{Sc}, \mathrm{Ga})$ Perovskite-Type Ionic Conductors," Dalton Trans., 19, 3061-6 (2004).

${ }^{45}$ M. E. Björketun, P. G. Sundell, and G. Wahnström, "Structure and Thermodynamic Stability of Hydrogen Interstitials in $\mathrm{BaZrO}_{3}$ Perovskite Oxide from Density Functional Calculations," Faraday Discuss., 134, 247-65 (2007).

${ }^{46}$ M. E. Björketun, P. G. Sundell, and G. Wahnström, "The Effect of Acceptor Dopants on the Proton Mobility in $\mathrm{BaZrO}_{3}$ : A Density Functional Investigation," Phys. Rev. B, 76, 054307-1-9 (2007). 